\title{
A 60 GHz Broadband Amplifier in SiGe Bipolar Technology
}

\author{
W. Perndl ${ }^{1,2}$, W. Wilhelm ${ }^{2}$, H. Knapp ${ }^{2}$, M. Wurzer ${ }^{2}$, K. Aufinger ${ }^{2}$, \\ T. F. Meister ${ }^{2}$, J. Böck ${ }^{2}$, W. Simbürger ${ }^{2}$, A. L. Scholtz ${ }^{1}$
}

\begin{abstract}
Student Paper
${ }^{1}$ Institute of Communications and Radio-Frequency Engineering, Vienna University of Technology Gusshausstrasse 25/389, A-1040 Vienna, Austria, e-mail: werner.perndl@infineon.com

${ }^{2}$ Infineon Technologies AG, Corporate Research, Otto-Hahn-Ring 6, D-81739 Munich, Germany
\end{abstract}

\begin{abstract}
A broadband amplifier with $16 \mathrm{~dB}$ gain and a 3-dB bandwidth of more than $60 \mathrm{GHz}$ is presented. This amplifier exhibits a 1-dB compression

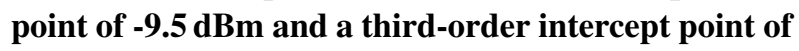
$+2.1 \mathrm{dBm}$ referred to the input. The maximum differential output voltage swing is $1.5 \mathrm{~V}_{\mathrm{PP}}$. Clear output eye diagrams have been measured up to $100 \mathrm{Gbit} / \mathrm{s}$. The chip is manufactured in an advanced SiGe bipolar technology and consumes a power of $770 \mathrm{~mW}$ at a supply voltage of $\mathbf{- 5 . 0} \mathrm{V}$.
\end{abstract}

\section{INTRODUCTION}

Broadband amplifiers are important building blocks for a large variety of applications, including wireless transceivers and optical communication systems. In general, they are based on a lumped or on a distributed concept.

Broadband amplifiers based on lumped elements are presented in [1], [2], and [3]. In [1] an amplifier using $\mathrm{SiGe}$ hetero junction bipolar transistors (HBTs) is presented which exhibits a gain of $36 \mathrm{~dB}$ and a bandwidth of $26 \mathrm{GHz}$. An InP HBT amplifier is presented in [2] with $21 \mathrm{~dB}$ gain and $38 \mathrm{GHz}$ bandwidth. Another InP HBT based wideband amplifier with bessel transfer function, a gain of $11 \mathrm{~dB}$, and a bandwidth of more than $50 \mathrm{GHz}$ is presented in [3].

Broadband amplifiers based on distributed concepts using InP high electron mobility transistors (HEMTs) are presented in [4] and [5] and exhibit a bandwidth of more than $110 \mathrm{GHz}$ and $92 \mathrm{GHz}$, respectively. A distributed amplifier using SiGe HBTs reaches a bandwidth of $80 \mathrm{GHz}$ [1].

In this paper a broadband amplifier based on lumped elements using an advanced SiGe bipolar technology is presented. Key design aspects are high bandwidth and a high output voltage swing. The amplifier is intended as driver circuit for both sinusoidal signals up to high frequencies and very high data rate signals.

\section{TECHNOLOGY}

The amplifier is fabricated in a preproduction stateof-the-art SiGe bipolar technology [6]. The transistors have a double-polysilicon self-aligned emitter-base configuration with a minimum effective emitter width of $0.14 \mu \mathrm{m}$. A TEM cross section of the emitter-base complex is given in Fig. 1. The SiGe:C base of the transistors has been integrated by selective epitaxial growth. The emitter contact exhibits a monocrystalline structure. The transistors manufactured in this technology offer a transit frequency $\mathrm{f}_{\mathrm{T}}$ of $200 \mathrm{GHz}$, a maximum oscillation frequency $\mathrm{f}_{\max }$ of $275 \mathrm{GHz}$ and a ring oscillator gate delay of $3.5 \mathrm{ps}$. Current density for maximum $\mathrm{f}_{\mathrm{T}}$ and $\mathrm{f}_{\max }$ is at about $8 \mathrm{~mA} / \mu \mathrm{m}^{2}$. Some important parameters of a tran-

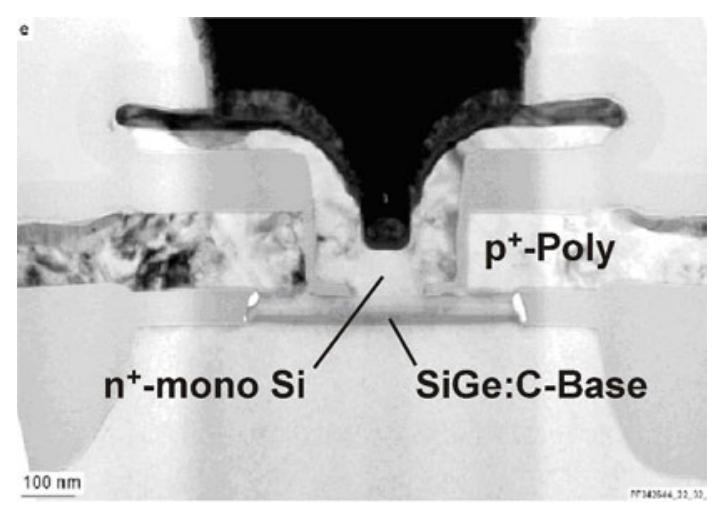

Figure 1: TEM cross section of the emitter-base complex of a transistor with effective emitter width of $0.14 \mu \mathrm{m}$ 
IEEE BCTM 15.4

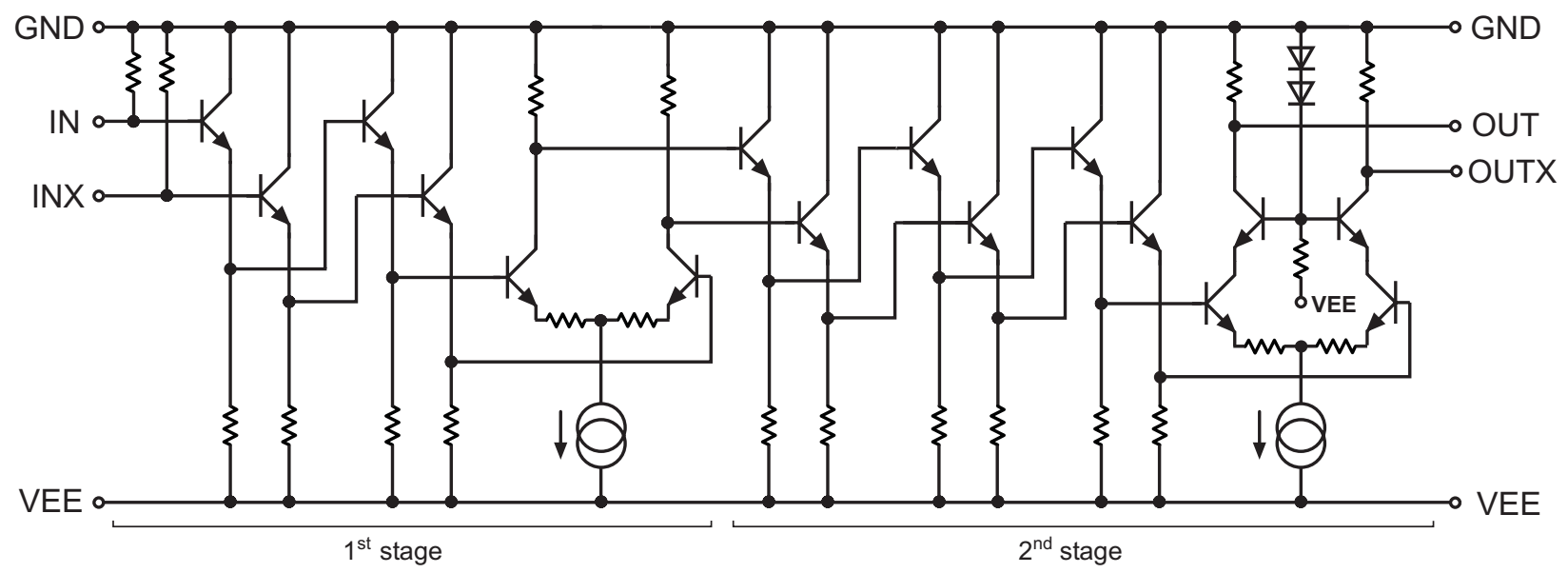

Figure 2: Schematic of the broadband amplifier

sistor with an effective emitter size of $0.14 \mu \mathrm{m} \times 2.6 \mu \mathrm{m}$ are: $\mathrm{C}_{\mathrm{BC}}=5.5 \mathrm{fF}, \mathrm{C}_{\mathrm{EB}}=6.3 \mathrm{fF}, \mathrm{C}_{\mathrm{CS}}=3.7 \mathrm{fF}, \mathrm{R}_{\mathrm{B}}=50 \Omega$, $\mathrm{R}_{\mathrm{E}}=3.5 \Omega, \mathrm{R}_{\mathrm{C}}=7.5 \Omega$. The collector-emitter breakdown voltage $\mathrm{BV}_{\mathrm{CE} 0}$ is $1.7 \mathrm{~V}$.

The technology provides four copper metallization layers, two different types of polysilicon resistors, a TaN thin film resistor and a MIM capacitor.

\section{CIRCUIT DESIGN}

The circuit diagram of the broadband amplifier is shown in Fig. 2. The broadband amplifier is based on a fully differential design and consists of two stages. The first stage consists of two emitter follower pairs and a

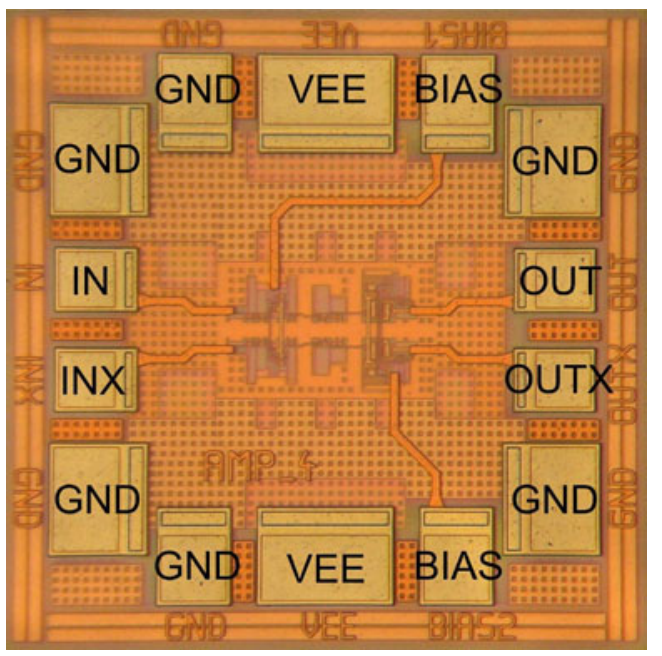

Figure 3: Chip photograph (chip size: $550 \mu \mathrm{m} \times 550 \mu \mathrm{m})$ differential amplifier. The second stage consists of three emitter follower pairs and the differential amplifier at the output. $50 \Omega$ on-chip resistors are provided at the input and the output for broadband matching. In order to achieve a high output swing, high currents in the differential amplifiers are necessary. In addition, emitter degeneration and low load resistors are used for increasing the 3-dB bandwidth at a well-defined gain. Emitter degeneration resistors also improve the linearity of the circuit. As an adequate dimensioning for the first stage we obtained load resistors of $30 \Omega$ and emitter degeneration resistors of $10 \Omega$ each. In the second stage emitter degeneration resistors of $5 \Omega$ are used. Carefully adjusted transistor sizes and currents enable a flat transfer function and a high bandwidth. The differential amplifier of the second stage is implemented as cascode configuration in order to prohibit avalanche breakdown of the output transistors. The cascode stage additionally minimizes the Miller effect, thereby bandwidth is increased.

\section{EXPERIMENTAL RESULTS}

In Fig. 3 a chip photograph of the broadband amplifier is shown. The die size is $550 \mu \mathrm{m} \times 550 \mu \mathrm{m}$. The amplifier has been carefully characterized by S-parameter and large-signal measurements. All measurements have been performed at a supply voltage of $-5 \mathrm{~V}$ with a current consumption of $155 \mathrm{~mA}$.

S-parameter measurements have been performed single-ended, on-wafer using an Anritsu 360B vector network analyzer with $67 \mathrm{GHz}$ GS and SG probes, respectively. Fig. 4 shows the single-ended measured gain and the input and output return loss at $50 \Omega$ source and load impedance. The single-ended low-frequency gain 


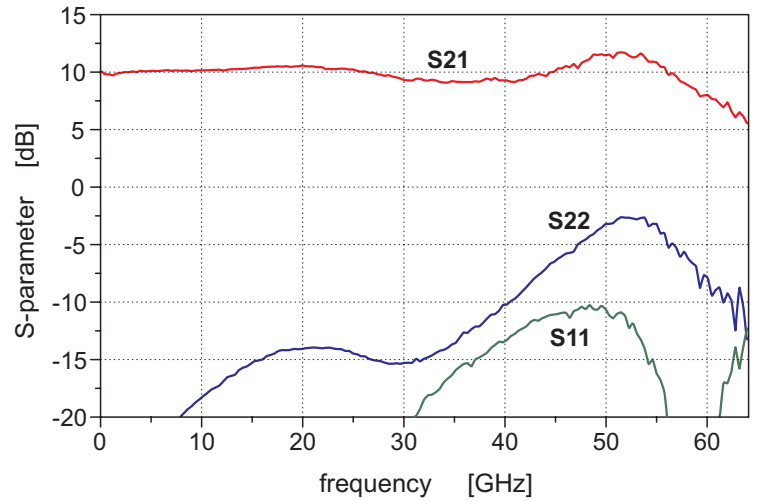

Figure 4: Single-ended on-wafer measurement of the Sparameters

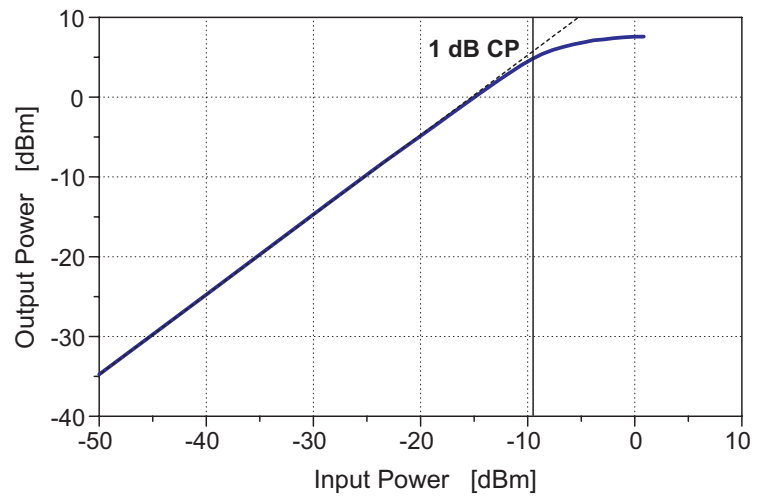

Figure 5: Differential on-wafer measurement of the 1-dB compression point (input frequency: $40 \mathrm{GHz}$ )

is $10 \mathrm{~dB}$ and the $3-\mathrm{dB}$ bandwidth is $62 \mathrm{GHz}$. The differential gain is $16 \mathrm{~dB}$. Degradation of $\mathrm{S}_{22}$ at about $50 \mathrm{GHz}$ can be observed. In the case of a single-ended excitation together with an inductance in the supply path this behavior can be verified by simulations. In differential operation such an inductance would have no effect.

The large-signal behavior of the broadband amplifier is analyzed on-wafer with $40 \mathrm{GHz}$ GSSG-probes using differential signals. In Fig. 5 the $1-\mathrm{dB}$ compression point of the amplifier is shown. It results to $-9.5 \mathrm{dBm}$ referred to the input, measured at a signal-frequency of $40 \mathrm{GHz}$. Fig. 6 shows the third-order intermodulation for a two-tone excitation with input frequencies of $40 \mathrm{GHz}$ and $40.002 \mathrm{GHz}$. The input-referred third-order intercept point is $+2.1 \mathrm{dBm}$.

Further measurements have been performed by excitation with high data rate signals. Therefore a PRBSgenerator chip [7] and the broadband amplifier chip have been mounted closely on a substrate. Short bond wires

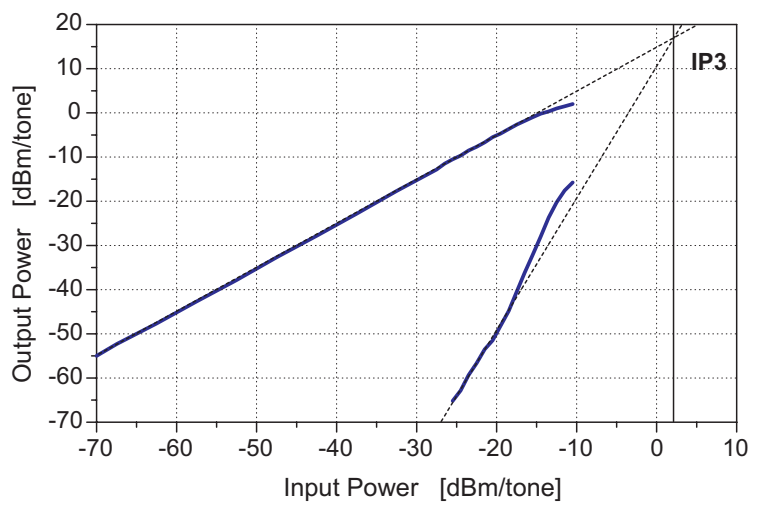

Figure 6: Differential on-wafer measurement of the third-order intercept point (input frequencies: $40 \mathrm{GHz}$ and $40.002 \mathrm{GHz}$ )

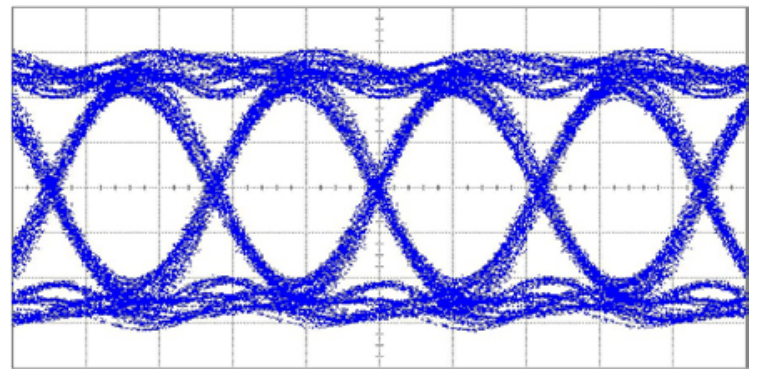

Figure 7: Measured $80 \mathrm{Gbit} / \mathrm{s}$ differential output eye diagram $(250 \mathrm{mV} / \mathrm{div}, 5.6 \mathrm{ps} / \mathrm{div})$

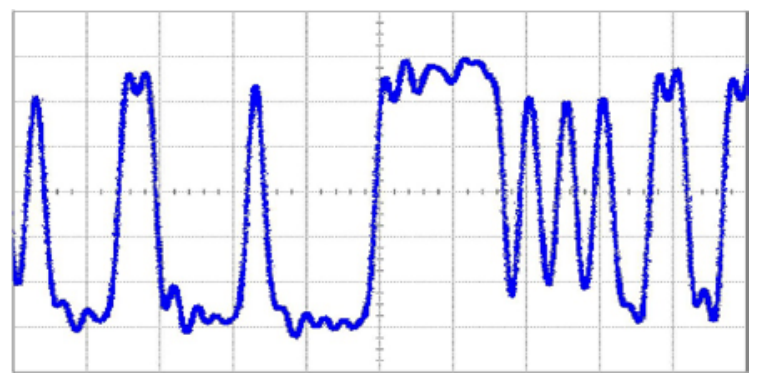

Figure 8: Measured $80 \mathrm{Gbit} / \mathrm{s}$ differential output signal (250 mV/div, $50 \mathrm{ps} / \mathrm{div})$

connect the outputs of the PRBS-generator and the amplifier inputs. The output signal has been measured with a $40 \mathrm{GHz}$ GSSG-probe and a $70 \mathrm{GHz}$ sampling oscilloscope $86100 \mathrm{~B}$ from Agilent. Fig. 7 shows the differential $80 \mathrm{Gbit} / \mathrm{s}$ output eye diagram. The amplitude is $2 \times 750 \mathrm{mV}_{\mathrm{PP}}$ and the eye opening is about $1 \mathrm{~V}$. In Fig. 8 the bit pattern of the same signal is shown. The amplitude of the input signal is about $2 \times 150 \mathrm{mV}_{\mathrm{PP}}$. In Fig. 9 
Table 1: Summary of technical data

\begin{tabular}{|c|c|}
\hline \hline Technology & $200 \mathrm{GHz} \mathrm{f}_{\mathrm{T}}$ SiGe bipolar \\
\hline Supply voltage & $-5.0 \mathrm{~V}$ \\
\hline Supply current & $155 \mathrm{~mA}$ \\
\hline Differential gain & $16 \mathrm{~dB}$ \\
\hline 1-dB compression point & $-9.5 \mathrm{dBm}$ (input) \\
\hline Third-order intercept point & $+2.1 \mathrm{dBm}$ (input) \\
\hline Chip size & $550 \mu \mathrm{m} \times 550 \mu \mathrm{m}$ \\
\hline
\end{tabular}

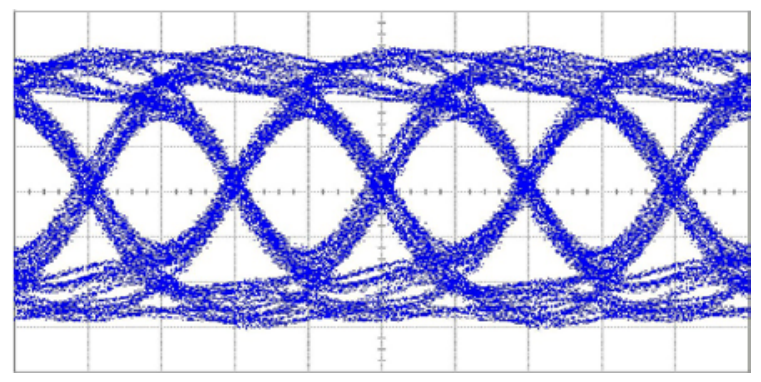

Figure 9: Measured $100 \mathrm{Gbit} / \mathrm{s}$ differential output eye diagram $(250 \mathrm{mV} /$ div, $5 \mathrm{ps} /$ div $)$

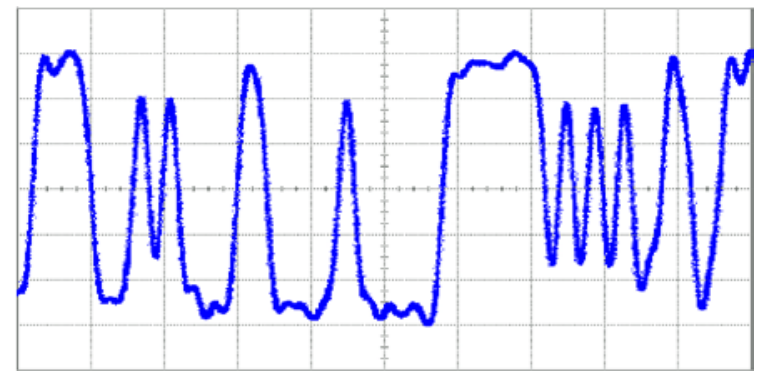

Figure 10: Measured $100 \mathrm{Gbit} / \mathrm{s}$ differential output signal (250 mV/div, $50 \mathrm{ps} / \mathrm{div})$

and Fig. 10 the output eye diagram and the output bit pattern for a $100 \mathrm{Gbit} / \mathrm{s}$ excitation signal are shown. At this data rate both the input signal and the limited bandwidth of the measurement equipment degrade the measured output signal.

\section{SUMMARY}

In this paper a monolithic integrated broadband amplifier in SiGe bipolar technology is presented. The circuit exhibits a differential gain of $16 \mathrm{~dB}$, a bandwidth of $62 \mathrm{GHz}$ and it consumes $155 \mathrm{~mA}$ at a supply voltage of $-5 \mathrm{~V}$. Tab. 1 gives a summary of the circuit performance.

To the author's knowledge, this is the highest bandwidth for lumped broadband amplifiers reported so far.
The clear output eye diagrams at a data rate of $80 \mathrm{Gbit} / \mathrm{s}$ and beyond demonstrate the feasibility for high data rate communication.

\section{REFERENCES}

[1] O. Wohlgemuth, P. Paschke, and Y. Baeyens, "SiGe broadband amplifiers with up to $80 \mathrm{GHz}$ bandwidth for optical applications at $43 \mathrm{Gbit} / \mathrm{s}$ and beyond", Proc. of the European Microwave Conference, 2003, pp. 1087-1090.

[2] Y. Baeyens, G. Georgiou, J. S. Weiner, A. Leven, V. Houtsma, P. Paschke, Q. Lee, R. F. Kopf, Y. Yang, L. Chua, C. Chen, C. T. Liu, and Y. K. Chen, "InP D-HBT ICs for 40-Gb/s and Higher Bitrate Lightwave Transceivers", IEEE Journal of Solid-State Circuits, vol. 37, no. 9, pp. 1152-1159, Sept. 2002.

[3] D. Choudhury, M. Mokhtari, M. Sokolich, and J. F. Jensen, "DC to $50 \mathrm{GHz}$ Wideband Amplifier with Bessel Transfer Function", 2004 IEEE Radio Frequency Integrated Circuits Symposium, June 2004, pp. 329-332.

[4] S. Masuda, T. Hirose, T. Takahashi, M. Nishi, S. Yokokawa, S. Iijima, K. Ono, N. Hara, and K. Joshin, "An Over 110-GHz InP HEMT Flip-chip Distributed Baseband Amplifier with Inverted Microstrip Line Structure for Optical Transmission Systems ", IEEE GaAs IC Symposium 2002 Tech. Digest, 2002, pp. 99-102.

[5] C. Meliani, G. Rondeau, G. Post, J. Decobert, W. Mouzannar, E. Dutisseuil, and R. Lefèvre, "A high gain-bandwidth product InP HEMT distributed amplifier with $92 \mathrm{GHz}$ cutoff frequency for $40 \mathrm{Gbit} / \mathrm{s}$ applications and beyond", IEEE GaAs IC Symposium 2002 Tech. Digest, 2002, pp. 103106.

[6] J. Böck, K. Aufinger, R. Stengl, S. Boguth, R. Schreiter, M. Rest, H. Knapp, M. Wurzer, W. Perndl, T. Böttner, and T. F. Meister, "SiGe Bipolar Technology for Automotive Radar Applications", accepted for 2004 Bipolar/BiCMOS Circuits and Technology Meeting, Sept. 2004.

[7] H. Knapp, M. Wurzer, W. Perndl, K. Aufinger, T. F. Meister, and J. Böck, "100-Gb/s $2^{7}-1$ and 54-Gb/s $2^{11}-1$ PRBS Generators in SiGe Bipolar Technology", accepted for 2004 IEEE Compound Semiconductor IC Symposium, Oct. 2004. 